\title{
What is Parent Engagement in Early Learning? Depends Who You Ask
}

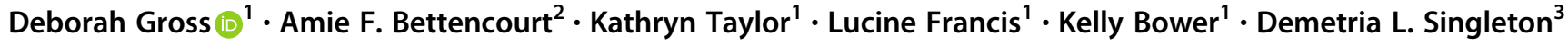

Published online: 10 December 2019

(c) The Author(s) 2019

\begin{abstract}
Objectives Parent engagement in early learning has historically been defined quite broadly and it is unclear whether those designing, implementing, evaluating, or participating in parent engagement initiatives conceptualize parent engagement in the same way. Lack of consensus could contribute to poor quality of parent-school partnerships and reliance on parent engagement measures and strategies that lack meaning and utility. We explored and compared definitions and characteristics of parent engagement in early learning across multiple stakeholders in one urban school district serving predominantly lowincome, African American, and Latinx families.

Methods Using a qualitative descriptive design, we individually interviewed 63 parents $(n=23)$, teachers $(n=8)$, early childhood staff $(n=8)$, district leaders $(n=7)$, and community leaders $(n=8)$ to understand how each defined parent engagement in early learning and the characteristics they believed were indicative of an engaged parent.

Results Nine different definitions were described; the majority centering on parents' responsibilities for ensuring engagement. We found wide differences within and across stakeholder groups in how parent engagement is defined and operationalized.

Conclusions There was little consensus in how parent engagement was conceptualized, suggesting there may be different working models for how stakeholders believe parent engagement supports early learning. Three potential parent engagement models are discussed in relation to the qualitative findings. This is the first study to directly compare different stakeholders' perspectives about parent engagement in early learning in an urban school system serving a large number of low income families and families of color.
\end{abstract}

Keywords Parent engagement $\cdot$ Parent involvement $\cdot$ Family engagement $\cdot$ Early childhood education $\cdot$ Early learning

The importance of parent engagement in children's learning has been well documented (Powell et al. 2010; Wilder 2014). Numerous studies have shown that parent engagement, beginning as early as the preschool years, has positive effects on children's literacy and math skills (Fantuzzo et al. 2004; Van Voorhis et al. 2013; Wilder 2014). Based on the evidence, parent engagement has become a core component of education policy. For example, the United States Department of Education (USDE) requires all Title I

Deborah Gross

debgross@jhu.edu

1 Johns Hopkins School of Nursing, 525N. Wolfe Street, Baltimore, MD 21205, USA

2 Johns Hopkins School of Medicine, Baltimore, MD, USA

3 Baltimore City Public Schools, Baltimore, MD, USA schools (i.e., schools serving a high proportion of lowincome students) to have a "parent involvement" policy and a plan for how schools and parents will collaborate to promote student achievement (Mapp 2012).

Parent engagement (also referred to as parent involvement and family engagement) is a complex and broadly defined term (Hayakawa et al. 2013; Van Voohis et al. 2013). The USDE defines it as the participation of parents and educators in "regular, two-way, and meaningful communication involving student academic learning and other school activities" (United States Department of Education 2015). The Center for Disease Control and Prevention defines parent engagement as parents and schools working together to support and improve students' learning, development, and health (Centers for Disease Control and Prevention 2012). The National Association for Family, School and Community Engagement defines parent engagement as a shared responsibility to actively support children's 
learning and development (National Association for Family (n.d.)). Although these official definitions all reflect a shared commitment between educators and parents working together to support children's learning, they are conceptually broad and provide little guidance for designing or evaluating effective parent engagement strategies.

To further define this construct, a number of parent engagement models capturing the different ways parents demonstrate their involvement in their children's education have been advanced. For example, Van Voorhis et al. (2013) identified four categories of parent involvement: learning activities at home that parents use to promote their children's literacy and math skills, family participation in school- and classroom-based activities, school outreach activities designed to engage families to make them feel included and welcome, and supportive parenting activities that promote children's developmental well-being. Fantuzzo et al. (2000) created a measure of parent engagement in early learning that focused on three types of involvement: school-based involvement (i.e., active participation in school- and classroom-based activities), home-school conferencing (i.e., parent-school communications), and homebased involvement (i.e., activities parents initiate outside of school to support their children's learning). These models of parent engagement have been important for adding focus and structure to the concept of parent engagement and have been widely cited (e.g., McWayne et al. 2008; Powell et al. 2010).

However, it is unclear whether educators and parents hold similar views about what they believe are relevant parent engagement activities and their respective responsibilities for supporting children's learning. For example, parents may view parent engagement as a set of behaviors or values communicated to children in the home such as providing homework support, reading with their children, or instilling values about the importance of a good education (Jarrett and Coba-Rodriguez 2017; McWayne et al. 2008). In contrast, educators may emphasize parent behaviors observable to them demonstrating parental commitment to supporting children's education such as parents volunteering in the classroom, chaperoning on field trips, participating on school committees, responding to school communications, and assuming leadership roles within the school (Child Trends 2013). These are very different conceptualizations of parent engagement. Given the importance of parent engagement for education policy and practice, there is surprisingly little research comparing how different stakeholders define and operationalize parent engagement.

Lack of consensus on how to define this important construct can contribute to low expectations of parents, demoralization among educators, inefficient use of school resources designed to foster and improve parent engagement, and biases toward single working parents who are unable to be more present in the school (Lareau and Horvat 1999). For example, using parent attendance at school functions as an indicator of parent engagement may lead to erroneous conclusions about parents' investment in their children's learning if only a handful of parents participate in these opportunities. Not surprisingly, parent engagement has also been described as "a value loaded term" (Bakker and Denessen 2007), in part because many common indicators of parent engagement may not be feasible for parents with limited resources or compatible with parents' beliefs about their role in supporting their children's learning (Jeynes 2010).

It is important to note that the theoretical framework typically used to guide parent engagement research, the bioecological model (Bronfenbrenner 1986) is also broad. Based on this model, parent engagement is conceptualized in terms of microsystem interactions (those between the child and their immediate environment, such as their family or their school) and mesosystem interactions (those occurring between two microsystems such as the child's family and school). An advantage of using a broad definition and theoretical framework is that characteristics of engaged parents can be adapted to different cultural and environmental contexts, an important quality in a public school system serving a highly diverse student population. However, the theory does not specify the processes that lead to parent engagement and children's academic success. This lack of theoretical precision may contribute to parent engagement policies and programs that are value-laden, not evidence-based, and not strategically designed to improve students' academic success (Global Family Research Project 2018)

Baltimore City Public Schools ("City Schools") serves a large number of low-income students and students of color; $73 \%$ of its schools are Title I schools and most students are African American or Latinx. Like many urban school districts, the majority of young children enter City Schools with limited kindergarten readiness skills (Baltimore City Public Schools 2018; Bettencourt et al. 2018). Nearly 65\% of Baltimore children live in single-parent households and many are exposed to significant hardships associated with urban poverty that can make it harder for children to learn and for parents to engage in their children's education (Data Resource Center for Child Health and Adolescent Health 2014).

This study explored and compared how different City Schools' stakeholders define and operationalize parent engagement in children's learning during pre-kindergarten (pre-k) and kindergarten. There is extensive research demonstrating that during the early years, parents play the central role in creating home environments that support 
brain development and learning (e.g., National Academies of Sciences, Engineering, and Medicine 2016). Given the importance of establishing strong connections with parents early in their children's education, and that parents who are not engaged in their children's education during these early years would be unlikely to engage in the later school years, this study focused specifically on parent engagement in early childhood education. Using a qualitative descriptive design, we individually interviewed parents, teachers, principals, early childhood staff, district leaders, and community leaders in Baltimore to understand (a) how they defined parent engagement and (b) what behaviors they believed were indicative of parents who were engaged in their child's learning.

\section{Methods}

\section{Participants}

Parents, principals, teachers, and early childhood staff were recruited from 16 elementary schools differing in geographic location, percent of students rated as "fully ready" on the annual kindergarten readiness assessment, percent of parents responding to annual school surveys (a proxy for parent participation rates), and grade bands served (i.e., pre$\mathrm{k}$ to 5th grade or pre-k to 8th grade). District administrators and community leaders were also recruited to participate. The final sample included 63 participants representing six Baltimore stakeholder groups: pre-k and kindergarten teachers $(n=8)$, principals $(n=8)$, other school-based staff $(\mathrm{n}=9)$, pre-k and kindergarten parents $(\mathrm{n}=23)$, district leaders $(n=7)$, and community leaders $(n=8)$.

Eligibility criteria for parents was being a parent or legal guardian (hereafter referred to as a "parent") of a pre-k or kindergarten child enrolled in one of the participating schools and able to speak English or Spanish. Consistent with the City Schools population, $60.8 \%$ of parent participants were African American and $21.7 \%$ were Latinx. Most were single parents $(52.2 \%)$, reported household incomes below $\$ 40,000(60.8 \%)$, had a high school diploma or less $(61.7 \%)$, and were employed full-time $(43.5 \%)$ or part-time (21.7\%). Fifty-two percent were parents of kindergarteners and of boys. We purposively recruited some parents whose voices are not typically included in parent engagement studies including monolingual Spanish speakers $(n=5)$, one parent who had been incarcerated, and one parent living in a shelter with her children. All study materials were available in Spanish and English.

Eligibility criteria for school-based staff was being employed at one of the 16 participating schools in a position that involved interacting with parents of young children (i.e., principal, pre-k or kindergarten teacher, school social worker, early childhood family support staff). Most schoolbased staff participants were female $(80.0 \%)$, African American (64.0\%), and experienced employees of City Schools, working for the district an average of 12.4 years $(\mathrm{SD}=9.6)$. Nearly half $(48 \%)$ had children who had attended City Schools.

Among community and district leaders, we recruited individuals involved in making practice and policy decisions on behalf of parents of young children in City Schools. Within City Schools, this included administrators leading district offices accountable for student outcomes linked to early learning or parent engagement. Within the community we sought leaders who directed community organizations that partner with City Schools, who had been identified as community leaders advocating on behalf of parents and families, or were elected policy makers known for their education focus. Most district and community leaders were female $(73.3 \%)$, White $(53.3 \%)$, and had a graduate degree $(80 \%)$. Twenty percent had children who had attended City Schools.

\section{Interview Procedures}

Interview guides were developed with an advisory board of parents, educators, and academic researchers with expertize in parent engagement. Interviewer training consisted of conducting at least one mock interview with an individual representing the same stakeholder group (e.g., teacher, parent). Audio recordings were critiqued by a senior member of the research team; adjustments were made as needed before commencing with study interviews. All research forms and interview questions were translated into Spanish by certified translators. Spanish-language interviews were administered by a bilingual interviewer and transcriptions were translated into English by a certified translator.

Interviews were conducted from November 2017 through April 2018 and each lasted approximately 20 to $40 \mathrm{~min}$. After providing consent, participants were first asked to describe their definition of parent engagement. Subsequent questions centered on behaviors they believed indicated a parent was engaged in their child's education and the nature of communication between parents and teachers they felt facilitated parent engagement (interview guides available upon request). At the conclusion of the interview, the interviewer repeated back the definition of parent engagement offered at the beginning of the interview and asked the participant if they felt that definition was still accurate after having thought more about the topic or if they wanted to amend it (i.e., member check). Some elaborated on their original comments but none changed their original definition. At the end of the interview, participants 
Table 1 Definitions of parent engagement by stakeholder group

\begin{tabular}{|c|c|c|c|c|c|c|}
\hline & $\begin{array}{l}\text { Principal } \\
n=8\end{array}$ & $\begin{array}{l}\text { Teacher } \\
n=8\end{array}$ & $\begin{array}{l}\text { Other staff } \\
n=8\end{array}$ & $\begin{array}{l}\text { District leader } \\
n=7\end{array}$ & $\begin{array}{l}\text { Community member } \\
n=8\end{array}$ & $\begin{array}{l}\text { Parent } \\
n=23\end{array}$ \\
\hline Definitions of parent engagement & 8 & 8 & 8 & 7 & 8 & 21 \\
\hline $\begin{array}{l}\text { Parents making sure the child goes to school and gets along } \\
\text { with others }\end{array}$ & 0 & 0 & 0 & 0 & 0 & 1 \\
\hline Parents being involved and helping in child's school & 3 & 1 & 1 & 0 & 0 & 4 \\
\hline Parent as decision maker and force within the school & 1 & 0 & 0 & 2 & 0 & 0 \\
\hline What the school does to make parents feel welcomed & 0 & 0 & 1 & 1 & 2 & 0 \\
\hline $\begin{array}{l}\text { Parents being actively involved in their child's life and } \\
\text { education }\end{array}$ & 3 & 4 & 4 & 2 & 2 & 13 \\
\hline Parents knowing how their child is progressing at school & 0 & 0 & 0 & 0 & 0 & 1 \\
\hline A partnership & 1 & 0 & 0 & 1 & 3 & 0 \\
\hline Two-way communication & 0 & 0 & 0 & 1 & 0 & 0 \\
\hline Diverse set of behaviors & 0 & 3 & 2 & 0 & 1 & 2 \\
\hline No definition provided & 0 & 0 & 0 & 0 & 0 & 2 \\
\hline
\end{tabular}

completed a demographic background form and received $\$ 20$ for their participation.

\section{Analytic Procedure}

Interview transcripts were imported into the f4analyze qualitative software (F4analyse 2019). Consistent with our aim of describing the phenomenon of parent engagement without preconceived notions of what that phenomenon should look like, we used a content analysis approach (Hsieh and Shannon 2005). Using this approach, codes and sub-codes emerged from the data through an inductive process.

Content analyses were conducted from March-May 2018. Initially, a random sample of 15 transcripts representing all stakeholder groups were open coded by the study team and an initial list of codes and definitions were generated. The team then discussed sub-codes consistent with each code, developed decision rules to increase coding consistency, and merged redundant codes and sub-codes. Once the full list of codes and sub-codes were developed, one team member (KT) coded the full set of transcripts, adding additional codes and sub-codes as needed in consultation with the larger team, and integrating them into the overall coding framework. Codebook revisions ceased once no new codes or sub-codes were identified (i.e., reached data saturation). A random sample of 10 (16\%) transcripts were independently coded by another team member (AFB) to assess inter-coder agreement. Mean inter-coder agreement was $83.17 \%$ (range $=60-100 \%$ ). Disagreements were addressed by consensus.

We examined the distribution of codes and sub-codes by stakeholder group to explore areas of consensus and divergence in how parent engagement was defined and operationalized. For parent engagement definitions, a single code was assigned for each participant based on the predominant focus of their response to how they defined the construct. A distribution of parent engagement definition codes was then created to summarize the number of participants within each stakeholder group whose definition reflected that code. We also developed a distribution of parent engagement behavior codes and sub-codes to summarize the number of participants within each stakeholder group who described behavioral indicators representative of that code or sub-code, regardless of the number of times that code or sub-code was described by the participant.

\section{Results}

\section{Definitions of Parent Engagement in Early Learning}

As shown in Table 1, stakeholders identified nine distinct definitions of parent engagement. The definition endorsed by the most participants across stakeholder groups was "parents being actively involved in their child's life and education". Of note, this was the definition most typically described by parents.

Overall just being there and supporting. Um, I mean it doesn't have to be just, a lot of people think that supporting is financial, but um, the time that you spend and just the investment that you put in in general is the engagement. Um, whether it be helping with homework, helping with projects, um, making sure you're getting you know, the child up on time. Not only for school but just for any events that they may be into. [Father of pre-k student] 
Parents knowing what the child is learning, what the expectations are, um, coming to school, being supportive of the child, reading with the child at night, at home, um, helping with homework, so just being involved in the education process. They don't necessarily have to be at the school all the time, but just showing that they know what their child is learning and being involved in the process of learning. [Pre-k teacher]

Several principals and educators defined parent engagement as "parents being involved and helping in the school". This definition was also described by some parents but none of the district leaders or community leaders.

Well, I think that parent engagement is basically having parents as an active participant in their child's education. And by active I mean um, coming to the school, volunteering. Um, participating in parent and community meetings. Um, going on trips, having a voice about the procedures and operations of the school. And even having some in, input into the budget and, and how moneys are spent and resources are used um, for their children. [Principal]

Eight participants defined parent engagement as a diverse set of behaviors they believed were indicative of an engaged parent but did not describe a unifying concept.

Parent engagement I just define as uh, parents that go to, go to PTA meetings. Um, parents that, that check your homework. Or see that you've even done. Parents that read flyers and, and notes and things that are sent home. It's just not sitting there in your book bag. Um, parents that read to you, talk to you, answer questions if they can. Um, spend, you know, some individual time with the child. [Great grandmother of a kindergartener]

... everything from conversing with them, taking them out, whether it's to the grocery store or to the playground. Checking up and see if there are any notices coming from the school. Uh, checking up on homework. You know, participating in field trips. Everything that um, and also looking at all aspects of a child development, like social, emotional..., but also play, you know, do some arts, do some science, whatever. You know, just a more balanced approach to parenting, and you know, just child development. [Pre-k teacher]
A number of participants struggled to define parent engagement in early learning. Two parents, both Latinx immigrant parents, commented that parent engagement was important but could not offer a definition.

Well, uh, personally, um, to me, for me it's very important, parent engagement in school, because, uh, the children feel it when you're there. And that helps them a lot there. Like my son, whenever I come, he gets very happy. [Mother of pre-k student]

Although the USDE defines parent engagement as "two-way communication" between parents and teacher/ schools, only one stakeholder, a district leader, described this definition. Indeed, only two of the definitions highlighted a shared responsibility between schools and parents in supporting parent engagement, "two-way communication" and "a partnership." Most definitions emphasized the parents' responsibility for parent engagement: "parents making sure the child goes to school and gets along with others," "parents being involved in the child's school/helping out in the school," "parent as decision maker and force within the school," "parents being actively involved in their child's life and education," and "parents knowing how their child is progressing at school". Only one definition, "what the school does to make parents feel welcomed" emphasized the school's responsibility for parent engagement, though none of the teachers or principals provided this definition. These findings suggest that (a) there is substantial diversity in how different stakeholders define parent engagement, (b) few stakeholders define parent engagement as a shared responsibility, and (c) most of the perceived responsibility for parent engagement appears to fall on parents.

\section{Behaviors Indicative of Parent Engagement}

Consistent with the models described in the literature (Van Voorhs et al. 2013), the parent engagement behavior codes described by the stakeholders included home-based parent engagement activities (includes 17 sub-codes), school-based engagement activities (includes 8 sub-codes), parents knowing what is happening at their child's school, parentschool-teacher communication (includes 5 sub-codes), parent trust in the school and the affective quality of the relationship between parents and teachers/schools, and parent knowing/understanding the impact they have on their children's learning. Each is described below and response frequencies are displayed in Table 2. 
Table 2 Behavioral indicators of parent engagement

\begin{tabular}{|c|c|c|c|c|c|c|}
\hline & $\begin{array}{l}\text { Principal } \\
n=8\end{array}$ & $\begin{array}{l}\text { Teacher } \\
n=8\end{array}$ & $\begin{array}{l}\text { Other staff } \\
n=8\end{array}$ & $\begin{array}{l}\text { District leader } \\
n=7\end{array}$ & $\begin{array}{l}\text { Community leader } \\
n=8\end{array}$ & $\begin{array}{l}\text { Parent } \\
n=23\end{array}$ \\
\hline Home-based parent engagement activities & 8 & 8 & 8 & 7 & 8 & 23 \\
\hline Does things to make learning fun & 0 & 0 & 0 & 0 & 1 & 3 \\
\hline Provides educational games, computer programs/apps, TV shows & 1 & 1 & 1 & 2 & 1 & 9 \\
\hline Makes clear expectations for good behavior at school & 1 & 1 & 0 & 2 & 0 & 7 \\
\hline Helps with homework & 5 & 7 & 6 & 3 & 5 & 18 \\
\hline Reads with their child & 7 & 4 & 5 & 4 & 7 & 10 \\
\hline Talks with their child & 5 & 6 & 4 & 3 & 5 & 9 \\
\hline Talks about their culture & 0 & 0 & 0 & 1 & 0 & 1 \\
\hline Talks about school & 0 & 1 & 1 & 1 & 1 & 6 \\
\hline Communicates to child that education is important & 1 & 1 & 2 & 1 & 4 & 12 \\
\hline Takes child to educational places & 2 & 1 & 1 & 2 & 3 & 8 \\
\hline Takes child to afterschool programs & 0 & 0 & 0 & 0 & 0 & 1 \\
\hline Encourages child to persevere and do their best & 1 & 1 & 1 & 0 & 1 & 12 \\
\hline Finds teachable moments & 1 & 6 & 2 & 1 & 2 & 5 \\
\hline Reinforces teaching at home & 0 & 0 & 1 & 1 & 0 & 1 \\
\hline Gets child ready for school & 4 & 3 & 0 & 1 & 2 & 4 \\
\hline Checks school materials & 5 & 3 & 1 & 2 & 0 & 3 \\
\hline Supports child's physical and emotional health & 1 & 2 & 3 & 4 & 3 & 4 \\
\hline Displays educational materials at home & 1 & 1 & 0 & 0 & 0 & 2 \\
\hline Creates a safe space for learning & 0 & 0 & 0 & 0 & 1 & 0 \\
\hline School-based parent engagement activities & 8 & 7 & 8 & 7 & 7 & 19 \\
\hline Volunteers in classroom or on field trips & 8 & 6 & 8 & 3 & 5 & 15 \\
\hline Attends school events & 7 & 4 & 7 & 4 & 5 & 8 \\
\hline Attends conferences to discuss child's learning or behavior & 5 & 2 & 4 & 1 & 2 & 7 \\
\hline Involved in decision-making at the school & 7 & 0 & 1 & 2 & 2 & 1 \\
\hline Transports child to/from school & 0 & 4 & 2 & 0 & 1 & 5 \\
\hline Ensures child's attendance at school & 4 & 1 & 2 & 2 & 3 & 2 \\
\hline Is present at the school & 3 & 0 & 2 & 5 & 2 & 6 \\
\hline $\begin{array}{l}\text { Parent knowledge about what is happening in their child's } \\
\text { school }\end{array}$ & 7 & 6 & 4 & 7 & 6 & 20 \\
\hline Parent-School-Teacher Communication & 8 & 8 & 8 & 7 & 8 & 22 \\
\hline Methods for communication & 7 & 6 & 6 & 6 & 4 & 22 \\
\hline Direction of communication & 8 & 8 & 8 & 7 & 8 & 19 \\
\hline Triggers for/content of communication & 8 & 7 & 8 & 6 & 6 & 18 \\
\hline Types of communication among parents, schools, and teachers & 1 & 2 & 0 & 1 & 2 & 1 \\
\hline Responsiveness of parent or teacher to communication & 4 & 4 & 3 & 2 & 1 & 4 \\
\hline $\begin{array}{l}\text { Parent trust of the school; feeling positive relationship with } \\
\text { schools/teachers }\end{array}$ & 7 & 6 & 8 & 6 & 8 & 20 \\
\hline $\begin{array}{l}\text { Parent knowing/understanding the impact they have on their } \\
\text { children's learning }\end{array}$ & 4 & 4 & 3 & 1 & 1 & 1 \\
\hline
\end{tabular}

Home-based parent engagement activities were described by every stakeholder interviewed. Although none of the home-based sub-codes were endorsed by all stakeholders, helping with homework, talking with their child, and reading with their child were described by the majority, with representation from every stakeholder group. Two participants described combining homework and talking to their child:

When you're at home, homework takes $10 \mathrm{~min}$. Talk to them during that time. Ask them how the school day went. A ten minute homework could turn into a 
twenty minute conversation without you even realizing it, because you're just engaged in conversation with your child. [Pre-k teacher]

Read to them. Um, read books to them and let them read books to the parent. Um, talk to them. I should put talk to them first... So talk to them is first, the more verbal communication uh, the better really. And talk to them about all manner of day-to-day interactions and really the best thing would be to um, push beyond to try to talk to them about things that they don't see every day. Talk to them, read to them, um, you know, as far as supporting early math skills go, uh, hands on and play with them. [District leader]

Other home-based sub-codes were described mostly by participants from only one or two stakeholder groups. For example, communicating to the child that education is important was described by the majority of parents and half of the community leaders but few principals, teachers, district leaders, and other school-based staff.

I actually told her that you don't wanna be, grow up and be no dummy. Always go to school and try your best. Um, I've actually shown her some like, people that's locked up, that has a second grade education. I said if you wanna be like them, fine. But if you wanna go to school and do better, that's what I need you to do... your school work is more important than anything else. I said the mind is a terrible thing to waste. She's like, it is? I said yeah, you'll understand when you get older." [Mother of kindergarten student]

Yeah, I, yeah I always tell her like [child's name], you gotta get a high school diploma cause you can't get a job. See, Mommy got a good job, right? Mommy works. So, you don't finish school, you won't be able to, you wanna be like Mommy right? So to be like Mommy, you gotta go to school. [Mother of pre-k student]

Uh, I think first just getting them to school, and valuing school. Um, talking to their kids about the importance of school and how important it is to be there every day and why it's important for them. [Community leader]

Similarly, encouraging the child to persevere and do their best was described by over half of the parents but only one principal, teacher, other school staff, and community leader and none of the district leaders. Here's how one parent described this engagement behavior:

Mmm. Like her report card. She'll show me it. Like, I know you can do it. You told me you could do it. You're very smart. I am smart. Yeah. Or she'll be um, she'll probably get frustrated with her work. So I'm like well, if you just take your time, I'll go over it with you, and maybe you'll understand it. Cause I don't want you to rush through it when you not gunna get it. You don't have to always be the first one done. So, she did it, she took her time. I said, see? See what happens when you take your time? .... Don't ever say you can't do something. Always try first. So she'll try, and then when she can't do it, then I'll help. But I, I don't give her the answer. [mother of kindergarten student]

Educators viewed home-based activities as an important aspect of parent engagement, although several commented that one could only assume home-based engagement using school-based observations, as described in this statement from a kindergarten teacher:

I can only assume. From what I've observed. Like, you know, I have children here who, no homework, never received the homework, and I do ask the parent about it, and there's always excuses, oh they didn't take the homework, they didn't bring the homework home, or she must have misplaced it, or he or she lost their, their book bag, or it was left in, all excuses, it was left in afterschool, and I'll even issue another one. And still I have, you know, it does not return, so."

In sum, there was strong consensus among stakeholders that parent participation in their child's education through home-based activities was an important dimension of parent engagement. However, there were notable differences across stakeholder groups in the kinds of home-based activities viewed as indicative of parent engagement.

School-Based Parent Engagement Activities were described by nearly all participants. The most common behavior identified across all stakeholder groups was volunteering in the classroom or on field trips. Volunteering in the classroom included a range of supportive behaviors by parents such as making cut-outs for class activities, reading to other children in the classroom, donating supplies or snacks, and serving as the class parent. However, many other volunteer activities extended well beyond the child's classroom, with the goal of supporting other parents' children or managing programs for the school. As one pre-k teacher described: 
Having parent leaders in the building and being able to give them activities to do with the children, or giving them a task to do like "hey we need to have um a book fair, here's the information, like you go and organize it. Or, um, we're gonna have a literacy night, like the teachers are gonna plan the, the educational activities, maybe you can come up with a couple of fun activities for the children.... Like really having that partnership where it takes some of that pressure off of the classroom teachers and like, we're working as a community."

One principal described their ideal vision for parent engagement as parents becoming such integral participants in school life that one might not be able to differentiate the parents from the teachers:

"It would just look like, honestly, it would like parents volunteering in classrooms and things like centers, and reading groups and reading just to children, and working with children on their mathematics. It would like like um, parents here and teachers are planning together. Um collaborating on individual learning plans for each child. Which is something that we're getting to. Um, it would like parents being able to come in and working with each other, parents on 'there's some great strategies that I use at home in this grade level'. Or 'here are some, you know, really great books that we use at home'... You know, it would just like look parents are here and you can't tell the parent from the teacher.

A district leader similarly described their vision of a school with a high degree of parent engagement as: parents in your classroom all the time, just helping, volunteering, bringing food, reading books, that would look like just parents in your building.

Many participants described parent attendance at school events as another indicator of parent engagement. However, only a minority of parents described attendance at school events as an indicator of school-based parent engagement.

Attendance at parent-teacher conferences, when analyzed as a separate sub-code, was described by relatively few teachers, district leaders, community leaders, or parents. This finding may reflect past experience with low parent turnout at parent-teacher conferences. As one kindergarten teacher explained:

...we'll have dates for conferences with parents. We'll send notices out. We'll send report cards out. We'll have them scheduled at a time that's convenient for them. Sometimes they won't even send back the, they won't even fill in the time slot. Sometimes when they do, they never show up. And that's a big problem for me because... we'll, you know, take a half day just to have [the conferences]. And parents, I'll have two or one parent of a 25, um a class of 25 . So that's depressing. That just speaks volumes like, okay, are these parents uninterested in their children's academics?

Being involved in decision-making at the school was described by a majority of principals as an indicator of parent engagement. However, none of the teachers and only one parent described this behavior as an indication of parent engagement. One principal shared:

And by active I mean um, coming to the school, volunteering. Um, participating in parent and community meetings. Um, going on trips, having a voice about the procedures and operations of the school. And even having some in, input into the budget and, and how moneys are spent and resources are used um, for their children.

It is noteworthy that parents ensuring their child attends school was described as an important parent engagement activity by half of principals but few other stakeholders. Indeed, district leaders were more likely to describe parents being present at the school than parents ensuring children are at the school.

In sum, school-based parent engagement activities were described by the majority of stakeholders as an important component of parent engagement although there were wide differences across stakeholders in the types of school-based activities described. Indeed, the only school-based behavior endorsed by the majority of stakeholders, including parents, was volunteering in the classroom or on field trips. Many of those volunteer activities were not specific to parents supporting their own child in the classroom but rather to supporting other people's children and broader school functions.

Parent knowledge of what is happening in their child's school was described as an indicator of parent engagement by a majority of participants in all stakeholder groups. One district leader described it as "...helping parents understand what's happening at school um, both in terms of the school's expectations and climate and culture, as well as what the learning is that's going on and what the learning expectations are, and just maintaining a continuous and open dialogue." This description of parent engagement is mirrored in the following quotes from a parent, a principal, and a community leader:

Um, I think being, just being involved with your child. You should know what your child is doing throughout their day in school. And you should 
always ask your child when they come home, like how was your day? What'd you learn in school and stuff like that. [Mother of a kindergarten student]

You know, um, parental engagement in a school means that parents are involved in, are aware of and involved in, multiple facets of what happens throughout the school. And not simply um, their own child, but the larger operations of the school. [Community leader]

In sum, parents knowing what is happening in their child's school was an important component of parent engagement across all stakeholders. How parents come to know what is happening in the child's school led many to talk about how information is communicated between parents and the school or teacher, as described below.

Although few participants defined parent engagement as "two-way communication," nearly everyone described Parent-School-Teacher Communication as a component of parent engagement. Sub-codes include communication methods, direction (i.e., who initiates communication), triggers for and content of communication, and responsiveness to communication.

Participants described different ways that parents, teachers, and schools communicate with one another beyond traditional face-to-face meetings at the school. One example was an online communication app used by some City Schools teachers, called "class Dojo":

...there's different communication devices... the teachers of the younger grades use class Dojo and that's an app for not only to support and recognize the positive behavior but it's also an app to actually communicate with parents. So if, you know, someone's having a good day, or not so good of a day, or something's coming up, that's a way of communication um, that parents are able to, you know, reach out. Two-way communication with the teacher. [Principal]

Many non-parent participants described using multiple forms of communication to connect with parents including newsletters, phone calls, email, flyers, texting, home visits, and social media. Despite the range of options now available for communicating with parents, many still acknowledged the centrality of a strong parent-teacher relationship to ensure parents attend to these communications:

We, we do a lot of text messages and phone calls. Um, but I don't think that any of that works if you don't have a relationship with your parents. [Paraeducator]
I text my parents at least once a week, so that they can get an update and just give them like reminders or send like a picture like, oh that's Wednesday, you might need to get over the hump, here's a picture of what so and so is doing in class. And so I personally keep in contact with every single one of my parents. [Pre-k teacher]

Parents also described various ways they communicate with their child's teacher and their communication preferences, which were sometimes dependent on the type of information being communicated. This perspective was described by the mother of a kindergarten student:

Um, I would prefer the [Class] Dojo. And, I mean she, if there's something that's, that's bad then she will call and contact you on the phone. But I prefer just the, the class Dojo and stuff.

Direction and triggers/content of communication were also described. Many participants acknowledged that parent engagement includes open communication between parents and teachers, which could be initiated by either. Some parents believed it was the teacher's responsibility to communicate with parents because it's the teachers who are with the child.

No, what I think is, because the children are in school, right? And I think that the teacher has to communicate with me...because I don't know how it's going for them in school. I don't do anything besides take them to school and then go pick them up. So the teacher has to communicate with me if he's good or if he's not good. [Mother of a pre-k student]

Half of the principals and teachers talked about parent responsiveness to teacher communication and four parents talked about teacher responsiveness to parents. Many comments related to frustration with parents for not being responsive to teachers as well as teachers not being communicative with parents:

Uh, you send home notices, cause I have an agenda that I inform the parents daily about their child's progress, behavior, and there are times when I like write a note, 'please can you call me, please reach me whenever you can,' you know, and no response, reply even with absences or tardiness. I reach out to the parents or even sometimes a sibling, you know, just, whatever route I can take to reach the parent and no response. Nothing. [Kindergarten teacher] 
Like, I know that she be busy because it's a whole 20 kids or whatever kids you got, it's just at least when you see the parent and like, if you feel like okay maybe you might have forgot something, so maybe you might need to just write down a note of, for each kid, like okay, [child name] might need help with this, he really need help in that, can you help him study in these certain areas. Stuff like that. [Father of a kindergarten student]

All stakeholders agreed that communication was important and the majority described preferred types of communication and who should initiate that communication and under what circumstances. Lack of responsiveness to communication was perceived by both parents and teachers as a problem that adversely affected parent engagement.

Parent trust in the school and the affective quality of the relationship between parents and schools/teachers was described by the majority of all stakeholders as an important indicator of parent engagement. This code focuses on the extent to which parents felt welcome in the school, perceived the school to have their and their child's best interests at heart, and felt comfortable communicating about their children with the teachers or other school staff. Parent trust was highlighted by some participants as particularly relevant for schools serving families of color who may expect that schools will not be welcoming places for them or their children and who may recall their own negative school experiences.

...we need to address the implicit bias that exists within teachers. I think, you know, if we take on and really tackle that internalized racism that exists among teachers who have internalized the idea of what the expectations are of the families and the young people that live in the communities, um, you know, that we have, and so tackling those biases and that institutional approach to education, um, really pushes families away, even when they want to be engaged. [Community leader]

This code also captured the extent to which parents and teachers felt honored, appreciated, and respected by one another.

Um, you know, teachers might be 'Oh I don't want them to have my email address, they'll email me all the time'. And it's like, no, if they know it's there, if they know they have access, they trust you that you're gunna let them know if something is up, and that they can always let you know, um and then they're not fighting for proof that we're taking care of their kids. [Principal]

We're working as a team so the kids can see like, teachers and parents are not enemies. Like, we are a team, we are all here on the same page and we're here for you, for your education. And, I think that just builds a whole community of just respecting education and knowing that education is important when you're all on the same team, and it's all a really positive place. [Pre-k teacher]

I love it when you come up, 'it's very nice to see you'. So they're really supportive and when you show your face, or when you try to go an extra mile with them or for them, they're, they say thank you. I mean it's, a thank you goes a long way. They're showing appreciation. Um, so just to have that feeling of hey, we're a team, going on, and that's definitely how they put it. [Mother of a pre-k student]

The code of parents knowing/understanding the impact they have on their children's learning captures the things parents say and do to communicate to their children that their education is important.

Um, I think this parent is engaged, one of the things that she always says is, um, she didn't have a parent that she felt invested in her education. Her, she had great parents, but they left everything up to the school. And she feels like she would have been a better student if she had had some support at home. So, this is our, one it's her only child. And she wants to make sure that her child's off to a really great start. And I agree with that a hundred percent. You can't entrust your child's learning to everyone but yourself. [Principal]

Um, because the children need to know one, education is important and if it's important to the parent it's important to the child... [children] just seem to learn more, they seem to like learning more, they enjoy school more, they're better behaved because they know their parent is involved and interested in what they're doing. [Pre-k teacher]

This code was described by many of the school-based stakeholders. However, only one parent described knowing the impact they have on their children's learning as an 
important indicator of parent engagement, suggesting that parents may underestimate their power to influence their children's education.

\section{Discussion}

This study compared different stakeholders' perspectives about parent engagement in early learning in an urban school district serving a large number of low-income families and families of color. Study participants represented important constituencies with a stake in how parent engagement policies are designed, implemented, and assessed in urban school districts serving a large portion of low-income families. Overall, we found little agreement among stakeholders in how they defined or operationalized parent engagement in early learning. Moreover, the majority of definitions described centered on parent engagement as a parent responsibility rather than a shared responsibility between parents and schools, as defined by USDE and the CDC. To our knowledge, this is the first study demonstrating the lack of consensus across parents, teachers, principals, other school staff, district leaders, and community leaders in how parent engagement in early learning is defined.

We also explored how stakeholders operationalized parent engagement. Participants described a wide range of engagement behaviors, many of which correspond to common typologies previously described in the literature including home-based activities, school-based activities, parent-teacher/school communication, and parent involvement in decision making within the school (Epstein 2010; Fantuzzo et al. 2013). However, within those typologies, stakeholders differed widely in the specific behaviors they believed were relevant indicators of parent engagement, highlighting the challenges of measuring a complex construct like parent engagement. For example, nearly all participants described a range of school-based parent engagement activities. However, only one school-based activity, "volunteering in the classroom or on field trips" was seen by most parents as a relevant indicator of parent engagement. Proportionally fewer parents described attending school events and conferences and being involved in decision making at the school as indicators of parent engagement, in contrast to the majority of principals who endorsed these behaviors. Similarly, every participant described home-based parent engagement activities though there was substantial diversity across and within stakeholder groups about the types of home-based activities engaged parents do with their children. These differences are important as they can lead to faulty assumptions about parents' levels of engagement in their children's learning, teachers feeling unsupported, and parents feeling blamed and unappreciated (Ishimaru and Takahashi 2017; Lareau and Horvat 1999).

There was near universal agreement that (a) parent trust and having a positive relationship with teachers and the school and (b) good parent-teacher/school communication were important components of parent engagement. As articulated by several participants, trust and communication are particularly important in a district serving a large population of families who may have experienced racism, economic discrimination, and negative school experiences when they were young (Iruka et al. 2011). Although we did not delve into parent engagement activities that fostered trust and communication, this would be an important area of future study.

Parent engagement is highlighted as a core component of US education policy because of its centrality in promoting children's academic success. As we studied the transcripts, we wondered how might these different engagement behaviors actually contribute to children's early learning and academic success? What are the perceived processes by which these parent engagement behaviors are believed to contribute to academic success? While home-based activities have been correlated with students' academic achievement (Boonk et al. 2018; Fantuzzo et al. 2013; Voorhis et al. 2013), how might volunteering in the school or being involved in decisionmaking at the school serve to support student achievement? Given that these school-based indicators of parent engagement were prominently featured in the interviews (and are common metrics for assessing parent engagement), understanding how stakeholders believe these activities contribute to students' academic success is important. Our findings suggest that there might be three working models for how parent engagement may support children's early learning and academic success: a parent investment model, a teacher investment model, and a social capital model. Each is described briefly below.

The parent investment model has been previously described by others (Gershoff et al. 2010; Longo et al. 2017). Briefly, parents invest in their children's futures by providing materials and supports that promote learning; self-esteem; and social, emotional, and behavior regulation skills. All of the home-based parent engagement activities described in this study are consistent with a parent investment model such as reading with children, helping with homework, being explicit with children about the importance of their education, and encouraging children to persevere. Moreover, there is extensive data demonstrating that these types of home based activities help children acquire skills and competencies that support learning (e.g., Mathis and Bierman 2015). There are also numerous evidencebased programs designed to help parents build their children's cognitive, language, and social-emotional skills 
during the early years (Gross et al. 2009; Nix et al. 2018; Sheridan et al. 2011).

A second parent engagement model is the teacher investment model in which teachers who feel supported by parents' invest more time and effort supporting that student's academic success. This model is consistent with comments such as engaged parents "take some of that pressure off of the classroom teachers," and an ideal level of parent engagement is "parents in your classroom all the time, just helping, volunteering, bringing food, reading books". This model is also consistent with research showing significant associations between teacher-perceived parent engagement and expectations for the student's academic success, particularly for children of color and children of immigrant parents (Dallaire et al. 2010; Ho and Cherng 2018). Indeed, parents may volunteer because they assume it will promote more positive teacher regard toward their child. However, there is no data demonstrating that parent volunteerism leads to improved early learning (e.g., Fantuzzo et al. 2013). There are also ethical problems with this model as teachers should equitably support all of their students, regardless of whether parents have the time and resources to volunteer in the school. Nonetheless, naming this model, and its ethical ramifications, may help educators become more aware of how the teacher investment model may be affecting their perspectives about parent engagement and attitudes toward children whose parents have not been present in the school.

A third parent engagement model that flowed from the data is the social capital model. Social capital has been broadly defined as the benefits and resources one gains from being part of a social network (Moore and Kawachi 2017). Participant comments about the importance of building a community where parents and teachers feel honored, appreciated, and respected; of parents feeling empowered to actively participate in school decision-making; and working as a team to support children's learning all point to a model in which parents are part of a school community that supports all of its members. The social capital model is consistent with two-generation programs like Head Start and community school models that invest in providing a range of services that support both parents' and children's growth and development while strengthening family-school relationships (Fiel et al. 2013; Kratochwill et al. 2009). Indeed, these kinds of parent engagement strategies have been linked to improved academic skills and classroom behavior (Powell et al. 2010) and reduced school mobility in more marginalized student populations (Fiel et al. 2013).

There are some important study limitations that warrant discussion. The results are specific to one urban school district in the mid-Atlantic region. Future research comparing stakeholder perspectives on parent engagement in other regions of the country is recommended, including rural communities where schools might face different types of parent engagement challenges. A strength of the study is that we over-sampled parents and purposively sought out participants who might face unique challenges engaging in their children's learning. However, the sample may have still been biased towards more engaged parents who saw and responded to the recruitment flyers posted at their child's school or sent home in the children's backpack.

The three proposed models require further study to understand parent engagement behaviors and the processes that contribute to children's early learning and academic success. Nonetheless, the results suggest that parents, principals, teachers, other school staff, district leaders, and community leaders hold different perspectives on what constitutes parent engagement, differences that have important implications for how we design, implement, and evaluate parent engagement initiatives in urban school districts serving low-income families.

Acknowledgements The authors gratefully acknowledge the contributions of the PEECE Project Advisory Board members Yolanda Abel, Kim Cox, Michelle Daniels, Corey Ennis Jr, Joyce Epstein, and Joseph Manko in developing the interview questions and Kristin Mmari for her guidance on earlier drafts of this manuscript.

Author Contributions D.G. designed and led the study and wrote the majority of the manuscript. A.F.B. collaborated on the study design, co-led the study, led the data analysis, and helped write and edit the manuscript. K.T. conducted the qualitative data analyses and helped write and edit the manuscript. L.F. collected interview data, participated in data analysis, and helped write and edit the manuscript. K.B. collected interview data, participated in data analysis, and helped write and edit the manuscript. D.L.S. collaborated on the study design, coled the study, helped write and edit the manuscript.

Funding This study was funded by a grant from the Institute of Education Science, US Department of Education through grant \#R305H170027. The opinions are those of the authors and do not represent views of the Institute or the US Department of Education.

\section{Compliance with Ethical Standards}

Conflict of Interest D.G., A.F.B., K.T., L.F., and K.B. have no conflicts of interest to declare. D.L.S. is employed by the Baltimore City Public Schools district.

Ethical Approval All procedures performed in studies involving human participants were in accordance with the ethical standards of the Johns Hopkins School of Medicine Institutional Research Board and the Baltimore City Public School Institutional Review Board.

Informed Consent Informed consent was obtained from all individual participants included in the study.

Publisher's note Springer Nature remains neutral with regard to jurisdictional claims in published maps and institutional affiliations. 
Open Access This article is distributed under the terms of the Creative Commons Attribution 4.0 International License (http://crea tivecommons.org/licenses/by/4.0/), which permits unrestricted use, distribution, and reproduction in any medium, provided you give appropriate credit to the original author(s) and the source, provide a link to the Creative Commons license, and indicate if changes were made.

\section{References}

Bakker, J., \& Denessen, E. (2007). The concept of parent involvement. Some theoretical and empirical considerations. International Journal about Parents in Education Copyright, 1, 188-199.

Baltimore City Public Schools. (2018). Results on kindergarten readiness assessment again show strength of City Schools' pre-K programs. Retrieved from: http://www.baltimorecityschools.org/ cms/lib/MD01001351/Centricity/Domain/1364/20180130_KRApressrelease-FINAL.pdf.

Bettencourt, A. F., Gross, D., Ho, G., \& Perrin, N. (2018). The Costly Consequences of not being socially and behaviorally ready to learn by kindergarten in Baltimore city. Journal of Urban Health, 95(1), 36-50. https://doi.org/10.1007/s11524-017-0214-6.

Boonk, L., Gijselaers, H. J. M., Ritzen, H., \& Brand-Gruwel, S. (2018). A review of the relationship between parental involvement indicators and academic achievement. Educational Research Review, 24, 10-30. https://doi.org/10.1016/j.edurev. 2018.02.001.

Bronfenbrenner, U. (1986). Ecology of the family as a context for human development. Developmental Psychology, 22(6), 19. T4Research Perspectives M4-Citavi. c:\%5CUsers\%5Cbfrank\% 5CDocuments\%5CCitavi 5\%5CProjects\%5CVeröffentlichungen \%5CCitavi Attachments\%5CBronfenbrenner1986 (2).pdf.

Centers for Disease Control and Prevention. (2012). Parent engagement: strategies for involving parents in school health. Atlanta, Georgia: Centers for Disease Control and Prevention.

Child Trends. (2013). Parental involvement in schools. http://www. childtrends.org/?indicators $=$ parental-involvement-in-schools.

Dallaire, D. H., Ciccone, A., \& Wilson, L. C. (2010). Teachers' experiences with and expectations of children with incarcerated parents. Journal of Applied Developmental Psychology, 31(4), 281-290. https://doi.org/10.1016/j.appdev.2010.04.001.

Data Resource Center for Child Health \& Adolescent Health. (2014). Adverse childhood experiences among Baltimore and Maryland's children. https://www.childhealthdata.org/docs/default-source/ local-area-synthetic-estimates/adverse-childhood-experiences-a mong-baltimore-maryland-s-children.pdf?sfvrsn $=$ b43903fd_4.

Epstein, J. L. (2010). School/family/community partnerships: caring for the children we share. Phi Delta Kappan, 92(3), 81-96. https://doi.org/10.1177/003172171009200326.

F4analyse. (2019). f4analyse. https://www.audiotranskription.de/ english/f4-analyse.

Fantuzzo, J., Gadsden, V., Li, F., Sproul, F., McDermott, P., Hightower, D., \& Minney, A. (2013). Multiple dimensions of family engagement in early childhood education: evidence for a short form of the Family Involvement Questionnaire. Early Childhood Research Quarterly, 28(4), 734-742. https://doi.org/10.1016/j. ecresq.2013.07.001.

Fantuzzo, J., Mcwayne, C., Perry, M. A., \& Childs, S. (2004). Multiple dimensions of family involvement and their relations to behavioral and learning competencies for urban, low-income children. School Psychology Review, 33(4), 467-480.

Fantuzzo, J., Tighe, E., \& Childs, S. (2000). Family involvement questionnaire: a multivariate assessment of family participation in early childhood education. Journal of Educational Psychology, 92(2), 367-376. https://doi.org/10.1037/0022-0663.92.2.367.

Fiel, J. E., Haskins, A. R., \& Turley, R. N. L. (2013). Reducing school mobility: a randomized trial of a relationship-building intervention. American Educational Research Journal, 50(6), 1188-1218. https://doi.org/10.3102/0002831213499962.

Gershoff, E. T., Aber, J. L., \& Lennon, M. C. (2010). Income is not enough: incorporating material hardship into models of income associations with parenting and child development. Child Development, 78(1), 70-95. https://doi.org/10.1111/j.1467-8624. 2007.00986.x.Income.

Global Family Research Project. (2018). Joining together to create a bold vision for next generation family engagement: engaging families to transform education. 32. https://globalfrp.org/Articles/ Joining-Together-to-Create-a-Bold-Vision-for-Next-GenerationFamily-Engagement-Engaging-Families-to-Transform-Educa tion.

Gross, D., Garvey, C., Julion, W., Fogg, L., Tucker, S., \& Mokros, H. (2009). Efficacy of the Chicago parent program with low-income African American and Latino parents of young children. Prevention Science, 10(1), 54-65. https://doi.org/10.1007/s11121-008-0116-7.

Hayakawa, M., Englund, M. M., Warner-Richter, M. N., \& Reynolds, A. J. (2013). The longitudinal process of early parent involvement on student achievement: a path analysis. National Head Start Association Dialog, 16(1), 103-126.

Ho, P., \& Cherng, H.-Y. S. (2018). How far can the apple fall? Differences in teacher perceptions of minority and immigrant parents and their impact on academic outcomes. Social Science Research, 74, 132-145. https://doi.org/10.1016/j.ssresearch.2018.05.001.

Hsieh, H.-F., \& Shannon, S. E. (2005). Three approaches to qualitative content analysis. Qualitative Health Research, 15(9), 1277-1288. https://doi.org/10.1177/1049732305276687.

Ishimaru, A.M., \& Takahashi, S. (2017). Disrupting racialized institutional scripts: Toward parent-teacher transformative agency for educational justice. Peabody Journal of Education, 92(3), 343-362.

Iruka, I.U., Winn, D.M., Kingsley, S. J., \& Orthodoxou, Y. J. (2011). Links between parent-teacher relationships and kindergarteners' social skills: Do child ethnicity and family income matter? The Elementary School Journal, 111(3), 387-408. https://www.jstor. org/stable/10.1086/657652.

Jarrett, R. L., \& Coba-Rodriguez, S. (2017). How African American mothers from urban, low-income backgrounds support their children's kindergarten transition: qualitative findings. Early Childhood Education Journal. https://doi.org/10.1007/s10643-017-0868-4.

Jeynes, W. H. (2010). The salience of the subtle aspects of parental involvement and encouraging that involvement: implications for school-based programs. Teachers College Record, 112(3), 747-774.

Kratochwill, T. R., McDonald, L., Levin, J. R., Scalia, P. A., \& Coover, G. (2009). Families and schools together: an experimental study of multi-family support groups for children at risk. Journal of School Psychology, 47(4), 245-265. https://doi.org/10. 1016/j.jsp.2009.03.001.

Lareau, A., \& Horvat, E. M. N. (1999). Moments of social inclusion and exclusion race, class, and cultural capital in family-school relationships. Sociology of Education, 72(1), 37-53. https://doi. org/10.2307/2673185.

Longo, F., Lombardi, C. M., \& Dearing, E. (2017). Family investments in low-income children's achievement and socioemotional functioning. Developmental Psychology, 53(12), 2273-2289.

Mapp, K. L. (2012). Title I and parent involvement: lessons from the past, recommendations for the future. Center for American Progress. Retrieved from: https://edsource.org/wp-content/uploads/ old/-title-i-and-parental-involvement_091556561921.pdf. 
Mathis, E. T. B., \& Bierman, K. L. (2015). Dimensions of parenting associated with child prekindergarten emotion regulation and attention control in low-income families. Social Development, 24, 601-620. https://doi.org/10.1111/sode.12112.

McWayne, C., Campos, R., \& Owsianik, M. (2008). A multidimensional, multilevel examination of mother and father involvement among culturally diverse Head Start families. Journal of School Psychology, 46(5), 551-573. https://doi.org/10.1016/j.jsp. 2008.06.001.

Moore, S., \& Kawachi, I. (2017). Twenty years of social capital and health research: a glossary. Journal of Epidemiology and Community Health, 71(5), 513-517. https://doi.org/10.1136/jech-2016-208313.

National Academies of Sciences, Engineering, and Medicine. (2016). Parenting matters: Supporting parents of children ages 0-8. Washington, D.C.: The National Academies Press. https://doi. org/10.17226/21868.

National Association for Family, School, and C. E. (n.d.). Family engagement defined. Retrieved from: https://nafsce.org/page/ definition.

Nix, R. L., Bierman, K. L., Motamedi, M., Heinrichs, B. S., \& Gill, S. (2018). Parent engagement in a Head Start home visiting program predicts sustained growth in children's school readiness. Early Childhood Research Quarterly, 45, 106-114. https://doi.org/10. 1016/j.ecresq.2018.06.006.

Powell, D. R., Son, S. H., File, N., \& San Juan, R. R. (2010). Parentschool relationships and children's academic and social outcomes in public school pre-kindergarten. Journal of School Psychology, 48(4), 269-292. https://doi.org/10.1016/j.jsp.2010.03.002.

Sheridan, M.M., Knoche, L.L., Kupzyk, K.A., Edwards, C.P., \& Marvin, C.A. (2011). A randomized trial examining the effects of parent engagement on early language and literacy: The Getting Ready intervention. Journal of School Psychology, 49(3), 361-383.

United States Department of Education. (2015). Every Student Succeeds Act (ESSA). United States Department of Education.

Van Voorhis, F. L., Maier, M. F., Epstein, J. L., \& Lloyd, C. M. (2013). The impact of family involvement on the education of children aged 3 to 8 . New York, NY Center on School, Familly and Community Partnerships, MDRC.

Wilder, S. (2014). Effects of parental involvement on academic achievement: a meta-synthesis. Educational Review, 66(3), 377-397. https://doi.org/10.1080/00131911.2013.780009. 